\title{
Uso do Scratch na Introdução de Conceitos de Lógica de Programação: relato de experiência
}

\author{
Carina Machado de Farias ${ }^{12}$, Anderson S. de Oliveira ${ }^{1}$, Everton Dias de A. Silva ${ }^{1}$ \\ ${ }^{1}$ Instituto Federal de Educação, Ciência e Tecnologia da Bahia (IFBA) \\ Av. Centenário, 500, Nazaré - Jacobina - Bahia, 44700-000, Brasil \\ ${ }^{2}$ Pesquisadora do Grupo de Pesquisa Automação, Eficiência Energética e Produção \\ carina.fariaseifba.edu.br, anderson.s.o@hotmail.com, \\ diasevertondive. com
}

\begin{abstract}
Learning programming is not a simple task for most of the students of the technical and superior courses in Informatics. This difficulty is reflected in the high rates of avoidance and disapproval in the introductory programming disciplines. Among the factors that influence the low performance of students and their difficulties in assimilating the contents of programming, the precarious logical-mathematical background of the students and the lack of previous experience in programming stand out. In order to promote a first contact with the students' programming, before the beginning of the classes, an extension project was carried out at the IFBA, Jacobina campus, where the students entering the Subsequent Information Technology Course participated in an introductory programming course, using the Scratch tool. This article reports on the effects of the project execution in relation to the failure rates in the Course of Programming of the said course in the second semester of 2017.
\end{abstract}

Resumo. Aprender programação não é uma tarefa considerada simples por grande parte dos estudantes dos cursos técnicos e superiores de Informática. Essa dificuldade é refletida nos altos índices de evasão e reprovação nas disciplinas introdutórias de programação. Dentre os fatores que influenciam o baixo rendimento dos alunos e suas dificuldades em assimilar os conteúdos de programação destacam-se o precário embasamento lógico-matemático dos estudantes e a falta de experiência prévia em programação. A fim de promover um primeiro contato com programação para os alunos, antes do início das aulas, foi realizado um projeto de extensão no IFBA, campus Jacobina, onde os alunos ingressantes no Curso Técnico Subsequente de Informática participaram de um curso introdutório de programação, utilizando a ferramenta Scratch. Este artigo relata os efeitos da execução do projeto em relação às taxas de reprovação na disciplina Lógica de Programação do referido curso no segundo semestre de 2017.

\section{Introdução}

A disciplina Lógica de Programação, presente nas primeiras etapas dos cursos técnicos e superiores da área de Computação, constitui a base de formação dos estudantes, requerendo deles uma nova forma de pensar e habilidades que dificilmente são 
desenvolvidas no ensino regular, levando os estudantes a terem grandes dificuldades e consequentemente apresentarem baixo rendimento durante o curso. (GUEDES, 2014)

Analisando os dados repassados pela Coordenação de Registros Escolares, do IFBA, campus Jacobina, ao longo dos anos de 2013 a 2016, percebe-se que grande parte dos alunos dos cursos técnicos de Informática apresenta dificuldades em assimilar as abstrações envolvidas nessa disciplina, levando a uma alta taxa de reprovação, como pode ser visto na Tabela 1.

Tabela 01: Aprovações e Reprovações na Disciplina Lógica de Programação

\begin{tabular}{|c|c|c|c|c|}
\hline INGRESSO & INICIANTES & APROVADOS & REPROVADOS & $\begin{array}{c}\text { TAXA DE } \\
\text { REPROVAÇÃO }\end{array}$ \\
\hline 2013.2 & 42 & 18 & 24 & $57,14 \%$ \\
\hline 2014.2 & 42 & 15 & 27 & $64,28 \%$ \\
\hline 2015.2 & 37 & 03 & 34 & $91,89 \%$ \\
\hline 2016.2 & 50 & 26 & 24 & $48 \%$ \\
\hline
\end{tabular}

A origem do problema das reprovações na disciplina de Lógica de Programação diz respeito a alunos, professores e até mesmo às metodologias utilizadas, sendo possível destacar alguns fatores que contribuem para o cenário atual: precária base lógico-matemática dos alunos; falta de dedicação aos estudos; limitações do professor; material didático de apoio ineficiente; etc.

Considerando a importância dessa problemática e buscando alternativas para minimizar o número de reprovações, foi desenvolvido no IFBA, campus Jacobina, um projeto de extensão que propôs introduzir os conteúdos da lógica de programação, de maneira contextualizada, e fazendo uso de estratégias e metodologias alternativas ao ensino tradicional, para os alunos matriculados no $1^{\circ}$ semestre do Curso Técnico Subsequente de Informática, visando promover um primeiro contato dos alunos com a área de programação antes do início das aulas, buscando, com isso, reduzir as dificuldades apresentadas pelos alunos no decorrer do semestre letivo. O curso fez uso da ferramenta Scratch, por ser uma ferramenta muito popular para o ensino de programação para quem não tem experiência prévia com a temática (SOUZA E CASTRO, 2016).

\section{Trabalhos Relacionados}

No decorrer dessa pesquisa foram encontrados alguns trabalhos que tratam de diferentes estratégias para tornar o processo de ensino-aprendizagem dos conteúdos de lógica de programação mais interessante, além da inclusão desses conteúdos na educação básica.

Em Friedrich et al. (2012), foi encontrada uma proposta de metodologia pedagógica para a inserção da lógica de programação para crianças de 7 a 10 anos de idade, fazendo uso do programa Logo e do projeto Lego Mindstorms.

Já Dias e Serrão (2014), relataram uma experiência do uso do Scratch com um grupo de alunos do primeiro ano do curso de Licenciatura da Computação. O trabalho 
analisou os efeitos que essa ferramenta promoveu sobre o aprendizado dos conceitos mais elementares de programação de computadores no grupo observado.

Gomes et al. (2014), usaram o Scratch com um grupo de meninas do ensino médio com o intuito de aumentar o interesse das meninas pela área de computação.

Ferreira et al. (2016) também buscaram incentivar jovens e adultos através da oferta de um curso de iniciação à programação de computadores às comunidades de Salvador e região metropolitana. Nesse projeto foram utilizadas as ferramentas Scratch e Visualg.

Algumas experiências com o ensino fundamental também foram encontradas, como o trabalho de Silva et al. (2016) que relata a aplicação do Scratch no ensino de programação para alunos de $5^{\circ}$ ano do ensino fundamental. Já Oliveira et al. (2014) e Farias et al. (2017), focaram nos alunos do $9^{\circ}$ ano do ensino fundamental da escola pública.

Souza e Castro (2016) apresentam uma revisão sistemática da literatura referente ao uso do Scratch no ensino de programação para crianças. O trabalho incluiu um total de 12 artigos publicados no período entre 2007 e 2016 e apontou que o Scratch tem sido uma ferramenta popularmente utilizada no ensino de programação para crianças. De forma semelhante, Batista et al. (2016), faz um apanhado de relatos de experiência sobre o uso do Scratch no ensino de programação em diferentes níveis de escolaridades, desde as séries iniciais do ensino fundamental, passando pelo ensino médio até chegar no nível superior. O trabalho concluiu que o Scratch se apresenta como uma ferramenta interessante que pode ser adequada a diferentes faixas etárias e pode ser utilizada para ensinar instruções básicas de programação, favorecendo o raciocínio lógico e desenvolvendo habilidades para solução de problemas.

\section{Ferramenta Scratch}

Scratch ${ }^{1}$ é um ambiente de programação desenvolvido pelo grupo de pesquisa Lifelong Kindergarten Group do Laboratório de Mídias do Massachusetts Institute of Technology (MIT), e tem por objetivo introduzir a programação de maneira fácil e rápida para aqueles que não possuem nenhum tipo de experiência, sendo apropriado para crianças a partir dos 8 anos de idade.

Em virtude do seu público alvo principal, a linguagem oferece um ambiente visual para programação, visando torná-la mais acessível que outras linguagens, disponibilizando uma interface que permite que programas sejam montados como blocos virtuais, arrastando-os para a área de trabalho, que é um plano de fundo estático, onde os elementos inseridos podem executar as suas ações. Para dar vida a seus projetos e definir o comportamento de cada um dos elementos presentes, os usuários associam a estes objetos sons, imagens e variáveis que podem ser manipulados pelos diferentes tipos de comandos fornecidos pela linguagem de programação do ambiente.

A linguagem Scratch disponibiliza comandos que permitem ao aprendiz trabalhar com conceitos computacionais importantes para iniciantes em programação, tais como, entrada e saída de dados, tipos de dados, variáveis, estruturas

\footnotetext{
${ }^{1}$ Disponível em https://scratch.mit.edu/
} 
de controle, operadores e arrays. Além disso, também permite trabalhar com comandos que conferem a natureza multimídia inerente a esta linguagem. Scratch pode ser acessado por meio de qualquer navegador de internet e conta também com uma versão desktop que é disponibilizada gratuitamente para download (SCRATCH, 2018).

\section{Condução do Projeto}

O projeto apresentado neste trabalho dá continuidade a um projeto anterior, realizado em 2016, onde se levantou o debate sobre o ensino dos conteúdos de lógica de programação para alunos da educação básica, envolvendo pedagogos, professores e alunos do campus. O resultado foi a criação de dois cursos de Lógica de Programação: um fazendo uso da ferramenta Scratch e outro da ferramenta S4A (Scratch for Arduino). Naquele primeiro momento, todos os planos de aulas e materiais pedagógicos foram produzidos pela equipe do projeto, e os cursos foram realizados, envolvendo alunos do $9^{\circ}$ ano do ensino fundamental da escola pública (FARIAS et al, 2017).

Nessa segunda etapa do projeto, com o material produzido na etapa anterior, foram realizadas as seguintes atividades:

- Revisão dos planos de aulas e do material pedagógico utilizados no curso de Lógica de Programação através do Scratch.

- Divulgação do curso para o público-alvo e inscrição dos interessados.

- Realização das aulas, análise dos resultados alcançados, pesquisa do veículo de publicação e escrita do artigo a ser publicado.

O curso foi realizado no período entre junho e julho de 2017 e teve 13 alunos inscritos, todos ingressantes no $1^{\mathrm{o}}$ semestre do curso Técnico Subsequente de Informática. As aulas aconteceram no laboratório de informática, contando com carga horária total de 30 horas, dividida em dois encontros semanais com duração de 3 horas, durante 5 semanas, totalizando 10 encontros. As aulas foram ministradas por dois alunos do Curso Superior de Licenciatura em Computação, orientados pela professora da disciplina de Lógica de Programação do campus.

A primeira aula foi realizada no pátio do campus, sem o apoio da ferramenta Scratch, e consistiu na realização de duas dinâmicas: "a fábrica de doces", que simulava o fabrico de um doce, a partir da definição dos ingredientes necessários, das etapas a serem seguidas e do produto gerado; e a "Caça ao Tesouro", onde de posse de um mapa ilustrado do campus, os alunos, agrupados em equipes, seguiam instruções que levavam a enigmas a serem solucionados a fim de encontrar pedaços de um algoritmo que deviam ser colocado em ordem. As dinâmicas tinham por objetivo explorar os conceitos de algoritmos, entrada, processamento e saída.

$\mathrm{Na}$ segunda aula, os alunos foram solicitados a responderem um formulário contendo perguntas como nome, idade, peso, altura, sexo, etc., sendo possível através das respostas explorar o conceito de tipos de dados. Em seguida foi realizada uma atividade denominada "Caixas-Variáveis", onde os alunos recebiam um algoritmo e caixas representando as variáveis desse algoritmo. Os alunos deveriam nomear as caixas e atribuir valores às caixas de acordo com a execução do algoritmo.

Ainda na segunda aula os alunos foram apresentados ao ambiente Scratch e a alguns exemplos criados utilizando o ambiente. Foi mostrado aos alunos como criar variáveis no ambiente e atribuir valores a elas. Ao final da aula os alunos foram capazes 
de construir um programa simples onde o usuário informava seu nome, que era armazenado na variável padrão "resposta" e o personagem gato dizia o valor armazenado na variável.

A terceira aula abordou os operadores aritméticos, relacionais e lógicos. Foi realizada uma dinâmica denominada "Jogo das Cartas", onde foram distribuídas cartas entre os alunos contendo valores numéricos e operadores aritméticos e lógicorelacionais, sendo que os alunos deveriam montar, usando as cartas recebidas, expressões que resultassem em valores verdadeiros. Para finalizar, os alunos foram incentivados a criar um jogo baseado no conceito da dinâmica utilizada na aula.

A quarta e quinta aulas exploraram a estrutura seqüencial de algoritmos, fazendo forte uso dos operadores aritméticos. Nessas aulas os alunos desenvolveram, utilizando o Scratch, várias calculadoras: calculadora das quatro operações básicas, calculadora do resto da divisão, calculadora de áreas de superfícies diversas (quadrados, triângulos, circunferências) e calculadora de troco.

As estruturas condicionais foram o foco das sexta e sétimas aulas. No decorrer dessas duas aulas os alunos foram estimulados a resolver problemas que envolviam a necessidade de uso dessas estruturas, utilizando o Scratch, como por exemplo: Conhecendo a idade de seu colega, decida se ele é maior ou menor de idade.

Nas últimas 03 aulas do curso foi trabalhado o conceito de estruturas de repetição. Mais uma vez o Scratch foi utilizado para desenvolver problemas que requeriam o uso dessas estruturas, tais como: mostrar a tabuada de multiplicação de um número qualquer.

Dos 13 alunos inscritos, 08 concluíram o curso com frequência igual ou superior a $75 \%$ da carga horária de $30 \mathrm{~h}$, o que representa $61,5 \%$ das inscrições. Ao final do curso, os alunos foram submetidos a um questionário que buscava conhecer a opinião dos alunos sobre o mesmo, tendo sido coletadas 08 respostas.

Quando perguntados sobre as principais dificuldades enfrentadas no decorrer do curso, todos manifestaram dificuldades de entendimento das questões envolvendo cálculos. Os alunos apresentaram desconhecimento dos operadores matemáticos e dificuldades com interpretação de texto, o que confirma os resultados já apontados em outros trabalhos, de que a falta de conhecimento matemático prévio dificulta $\mathrm{o}$ desenvolvimento do raciocínio lógico para programação de computadores.

Nenhum aluno se queixou de dificuldades em manusear o Scratch. Foi observado que uma vez que todos os participantes já possuíam contato com o computador, a relação com o Scratch ficou facilitada e os alunos não apresentaram dificuldades para manusear os blocos de comandos propostos pela ferramenta. Durante o curso, a versão web da ferramenta foi apresentada para os alunos e o instalador foi distribuído para práticas em suas residências.

Em relação à prática e persistência, observou-se que os alunos logo no início do curso não aceitavam a idéia de tentar realizar as atividades após um erro, assim perdendo o interesse em solucionar a questão. Isso era perceptível pelo fato de que a maioria dos alunos não costuma resolver problemas lógicos, e boa parte deles não se preocupa em compreender o domínio do problema, muitas vezes dando maior importância às respostas. 
Quanto à evasão apresentada durante o curso, foi identificado que a falta de transporte público no período de oferta do curso foi o principal fator determinante para a desistência dos alunos.

Todos os participantes declararam que se sentiram satisfeitos com o ensino e os métodos utilizados pelos ministrantes.

\section{Impactos na Disciplina Lógica de Programação}

Finalizado o curso de nivelamento, deu-se início às aulas da disciplina Lógica de Programação. Tal disciplina é obrigatória e presencial, com carga horária total de $60 \mathrm{~h}$, sendo ofertada aos alunos ingressantes no primeiro semestre do Curso Técnico Subsequente em Informática. O curso é composto por 04 semestres, sendo a disciplina de Lógica de Programação, a primeira das 04 disciplinas de programação ofertadas no decorrer do curso.

A disciplina foi ofertada para os alunos da turma ingressante no segundo semestre de 2017. Haviam 31 alunos matriculados na turma, entretanto, 08 alunos, embora matriculados, nunca assistiram a nenhuma aula.

Os 23 alunos restantes formaram dois grupos: Grupo A: 08 alunos que frequentaram o curso de Introdutório de Programação com Scratch; Grupo B: 15 alunos que não participaram do curso.

A disciplina foi dividida em 04 módulos. No primeiro módulo, foram introduzidos aos alunos os conceitos de lógica e algoritmos, usando ferramentas como descrição narrativa, fluxograma e português estruturado. A ferramenta Visualg foi utilizada para representar os algoritmos através do português estruturado.

No decorrer do primeiro módulo, os alunos resolveram 35 questões propostas sobre lógica e algoritmos, na forma de exercícios. Foram realizadas duas avaliações entre os alunos. A primeira avaliação abordou questões de raciocínio lógico e buscou avaliar o desenvolvimento dos alunos nesse aspecto. Um exemplo de questão utilizada nessa primeira avaliação pode ser visto no Quadro 1.

\section{Quadro 1: Exemplo de Questão de Raciocínio Lógico}

As irmãs Luciana, Rosana e Joana, de idades diferentes, possuem, cada uma delas, apenas um cachorro de estimação. Os cães se chamam Rex, Bob e Touro. Um é preto, o outro marrom e o outro branco. A ordem expressa na questão não representa a ordem das cores nem a ordem das donas. Sabe-se que Rex, um cachorro marrom, não é de Joana e pertence à irmã com idade do meio. Rosana, que não é a mais nova, tem um cachorro branco que não se chama Touro. De posse dessas informações, indique o nome de cada irmã, sua idade (mais velha, do meio ou mais nova), o nome e a cor de seu cachorro.

A segunda avaliação foi realizada no laboratório de informática e consistia em usar o Visualg para representar algoritmos para solucionar determinados problemas matemáticos simples. Essa atividade teve por objetivo avaliar a capacidade dos alunos ordenarem logicamente suas ideias a fim de construir uma solução para o problema dado e representar essa solução através do português estruturado. Um exemplo de questão utilizada nessa segunda avaliação pode ser visto no Quadro 2. 


\section{Quadro 2: Exemplo de Questão de Representação de Algoritmos usando Visualg}

Calcular e mostrar a quantidade de latas de tinta necessárias para pintar uma determinada área, em $\mathrm{m}^{2}$, fornecida pelo usuário. Considere que 1 litro de tinta cobre 15 $\mathrm{m}^{2}$, que uma lata de tinta tem 18 litros e que para um resultado melhor serão dadas duas demãos de tinta, ou seja, a área vai receber a pintura duas vezes.

$26 \%$ dos alunos da turma obteve aprovação no primeiro módulo, sendo que o grupo que frequentou o curso de Scratch teve desempenho melhor que o outro grupo, com $38 \%$ de aprovação contra $20 \%$ do outro grupo.

No segundo módulo os alunos foram introduzidos à Linguagem C. Nessa etapa os alunos tiveram contato com a sintaxe da linguagem e foram incentivados a desenvolver programas que solucionassem problemas matemáticos simples, que não exigiam o uso de estruturas de seleção nem de repetição.

No decorrer do módulo foram propostas 20 questões em forma de exercícios, e uma avaliação individual foi realizada no laboratório de informática, consistindo em construir um programa em linguagem de programação $\mathrm{C}$ para solucionar um dado problema matemático. A avaliação teve por objetivo verificar a capacidade do aluno em representar uma solução algorítmica fazendo uso da linguagem de programação $\mathrm{C}$. Avaliou-se também a compreensão do aluno sobre conceitos como: variáveis e constantes, tipos de dados, operações aritméticas, de atribuição, e de entrada e saída de dados. O Quadro 3 apresenta um exemplo de questão utilizada nessa etapa da disciplina.

\section{Quadro 3: Exemplo de Questão de Construção de Programas em Linguagem C}

Sobre o salário bruto de um funcionário são descontados $8 \%$ de INSS, $10 \%$ de IR e sobre o restante desconta-se 0,5\% referente à fíliação sindical. Escreva um programa em $\mathrm{C}$ que, ao ser fornecido o valor do salário bruto do funcionário, calcule e mostre:

1. O desconto referente ao INSS

2. O desconto referente ao IR

3. O desconto referente à filiação sindical

4. O total de todos os descontos

5. O salário líquido do funcionário.

Houve uma melhora no aproveitamento da turma como um todo no segundo módulo, sendo verificado que $43 \%$ da turma obteve êxito. Entretanto, ao analisar os dois grupos separadamente, observou-se que o desempenho do grupo A foi inferior ao do grupo $\mathrm{B}$, indicando que o Scratch não foi eficiente para preparar os alunos para programar em uma linguagem de programação de trabalho. Nesse módulo, apenas 38\% dos alunos que participaram do curso de Scratch foram capazes de construir de forma satisfatória um programa em Linguagem $\mathrm{C}$ para solucionar o problema proposto, contra $47 \%$ dos alunos que não participaram do curso.

O terceiro módulo contemplou as estruturas de decisão IF/ELSE e SWITCH/CASE. Nessa etapa os alunos continuaram a utilizar a linguagem de programação $\mathrm{C}$ para solucionar problemas, agora com maior grau de dificuldade. Os alunos deveriam ser capazes de utilizar as estruturas de decisão apresentadas e os operadores lógico-relacionais para compor soluções algorítmicas para os problemas propostos. 
Foram propostas 20 questões em forma de exercícios, e uma avaliação individual foi realizada no laboratório de informática, consistindo em construir um programa em linguagem de programação $\mathrm{C}$ para solucionar um dado problema envolvendo estruturas de decisão e operadores lógico-relacionais. A avaliação teve por objetivo verificar a capacidade do aluno em representar uma solução algorítmica fazendo uso das estruturas de decisão na linguagem de programação C. Avaliou-se também a compreensão do aluno sobre os operadores lógico-relacionais. O Quadro 4 apresenta um exemplo de questão utilizada nessa etapa da disciplina.

\section{Quadro 4: Exemplo de Questão de Construção de Programas em Linguagem C, exigindo Estruturas de Decisão}

Escreva um programa em linguagem de programação $C$ para funcionar em um hemocentro. O programa poderá ser usado por qualquer pessoa interessada em saber se ela preenche os requisitos para ser doadora de sangue.

O programa deverá solicitar a idade do usuário, seu sexo (1 - Masculino ou 2 Feminino), seu peso e a quantidade de dias decorridos da sua última doação.

O programa deverá responder ao usuário se ele atende ou não aos requisitos para doação de sangue ou plaquetas. Os requisitos são:

- $\quad$ Ter idade entre 18 e 69 anos;

- Pesar no mínimo $50 \mathrm{~kg}$;

- Não ter doado sangue nos últimos 90 dias, para mulheres, e nos últimos 60 dias, para homens.

No terceiro módulo foi registrada a evasão de 02 alunos, sendo 01 do grupo A, e 01 do grupo B. Dessa forma, os grupos passaram a ter 07 e 12 alunos respectivamente. Apesar dessas duas desistências, no terceiro módulo o desempenho da turma como um todo melhorou de forma acentuada, sendo verificado que $86 \%$ da turma obteve a nota mínima necessária para aprovação. Curiosamente, o mesmo percentual foi observado nos dois grupos quando analisados individualmente, o que nos leva a suspeitar que a turma como um todo trabalhou de forma mais colaborativa e menos competitiva. Nesse módulo não foi possível observar uma relação direta entre o êxito nas atividades e o contato prévio com o Scratch.

O quarto e último módulo da disciplina abrangeu as estruturas de repetição WHILE, DO/WHILE e FOR. A linguagem de programação $\mathrm{C}$ foi também utilizada nessa etapa para solucionar problemas que envolviam a necessidade de repetição de blocos de códigos. Os alunos deveriam ser capazes de utilizar as estruturas de repetição apresentadas para propor programas que solucionassem os problemas apresentados.

Foram propostas 20 questões em forma de exercícios, e uma avaliação individual foi realizada no laboratório de informática, consistindo em construir um programa em linguagem de programação $\mathrm{C}$ para solucionar um dado problema envolvendo estruturas de repetição. A avaliação teve por objetivo verificar a capacidade do aluno em representar uma solução algorítmica fazendo uso das estruturas de repetição na linguagem de programação C. O Quadro 5 apresenta um exemplo de questão utilizada nessa etapa da disciplina. 


\section{Quadro 5: Exemplo de Questão de Construção de Programas em Linguagem C, exigindo Estruturas de Repetição}
Sabendo que uma empresa possui 20 funcionários, faça um programa que leia o salário e o sexo de cada funcionário e informe quantos funcionários ganham mais de $\mathrm{R} \$ 1.000,00$ e quantas mulheres ganham acima de $\mathrm{R} \$ 5.000,00$. Informe ainda o menor e o maior salário e a média de salário entre homens e mulheres.

No último módulo houve mais uma evasão, dessa vez de um aluno do grupo B; o grupo A então permaneceu com 07 alunos e o grupo B com 13. Analisando o módulo final é possível verificar que o desempenho geral da turma foi inferior ao desempenho observado no módulo anterior, constatando-se uma aprovação de $80 \%$ da turma. Ao analisar os grupos individualmente, observou-se que mais uma vez o grupo A teve desempenho menor que o grupo $\mathrm{B}$, sendo observado que $71 \%$ dos alunos que participaram do curso de Programação com Scratch foram capazes de construir de forma satisfatória um programa em Linguagem $\mathrm{C}$ para solucionar o problema proposto, contra $85 \%$ dos alunos que não participaram do curso. Mais uma vez verificou-se que o curso de Scratch não influenciou positivamente para o êxito dos alunos. A Tabela 2 apresenta um resumo dos índices de aprovação em cada módulo e o resultado final da disciplina, separados por grupos.

Tabela 2: Índices de aprovação da turma por etapa

\begin{tabular}{|c|c|c|c|}
\hline Etapa & Grupo A & Grupo B & Turma \\
\hline Módulo I & $38 \%$ & $20 \%$ & $26 \%$ \\
\hline Módulo II & $38 \%$ & $47 \%$ & $43 \%$ \\
\hline Módulo III & $86 \%$ & $86 \%$ & $86 \%$ \\
\hline Módulo IV & $71 \%$ & $85 \%$ & $80 \%$ \\
\hline Resultado Final & $71 \%$ & $77 \%$ & $75 \%$ \\
\hline
\end{tabular}

\section{Considerações Finais}

Este trabalho apresentou a condução e os resultados obtidos com a oferta de um curso de Introdução à Lógica de Programação usando Scartch conduzido pela professora de Lógica de Programação e 02 alunos do Curso Superior de Licenciatura em Computação do IFBA, campus Jacobina.

Embora outros trabalhos apontem que o uso do Scratch na introdução de conceitos de programação tenham gerado resultados satisfatórios, do ponto de vista da aprovação dos alunos em disciplinas de Lógica de Programação, nessa experiência isso não foi possível ser comprovado. Ao contrário do que era esperado, o grupo que freqüentou as aulas com o suporte do Scratch apresentou taxas de aprovação sempre igual ou inferior ao grupo de controle, sendo superior apenas na avaliação que abordava os conhecimentos acerca do raciocínio lógico. Esse resultado nos leva a concluir que a ferramenta não foi eficiente no suporte à sintaxe rígida da Linguagem de Programação $\mathrm{C}$, uma vez que a linguagem utilizada no Scratch é muito mais lúdica e visual.

Diante dos resultados obtidos, pretende-se reaplicar o projeto em outras turmas futuras, a fim de se confirmar os resultados obtidos neste trabalho.

\section{Referências}


BATISTA, E. et al. Uso do Scratch no ensino de programação em Ponta Porã: das séries iniciais ao ensino superior. In: V Congresso Brasileiro de Informática na Educação/ XXII Workshop de Informática na Escola, 2016, Uberlândia - MG. Disponível em: http://br-ie.org/pub/index.php/wie/article/view/6863/4741.

DIAS, K. e SERRÃO, M. A Linguagem Scratch no Ensino de Programação: Um Relato de Experiência com Alunos Iniciantes do Curso de Licenciatura em Computação. In: XXXIV Congresso da Sociedade Brasileira de Computação, 2014, Brasília, DF. Disponível em: http://www.lbd.dcc.ufmg.br/colecoes/wei/2014/0017.pdf.

FERREIRA, A. C. et al. Hello World: relato de experiência de um curso de iniciação à programação. In: $\mathrm{V}$ Congresso Brasileiro de Informática na Educação, 2016, Uberlândia - MG. Disponível em: http://www.brie.org/pub/index.php/wcbie/article/view/7056/4930.

FARIAS, Carina Machado de et al. Uso de estratégias alternativas para o ensino de lógica de programação: relato de experiência em Jacobina, Bahia. In: XVII ESCOLA REGIONAL DE COMPUTAÇÃO BAHIA ALAGOAS SERGIPE (ERBASE) / WORKSHOP DE EDUCAÇÃO E INFORMÁTICA BAHIA-ALAGOAS-SERGIPE (WEIBASE), 2017, Cruz das Almas - BA. Disponível em: $<$ https://drive.google.com/drive/folders/1UZOpPF0YrPQHLgEZflxYfFAaMWnKbo 87>. Acesso em: 20 Nov. 2017.

FRIEDRICH, R. V. et al. Proposta metodológica para a inserção ao ensino de lógica de programação com logo e lego mindstorms. In XXIII Simpósio Brasileiro de Informática na Educação, 2012, Rio de Janeiro - RJ. Anais do Simpósio Brasileiro de Informática na Educação. Porto Alegre: SBC, 2012. Vol. 23, No. 1. Disponível em: http://www.br-ie.org/pub/index.php/sbie/article/view/1762/1523.

GOMES, W. et al. Incentivando meninas do ensino médio à area de Ciência da Computação usando o Scratch como ferramenta. In: III Congresso de Informática na Educação/XX Workshop de Informática na Escola, 2014, Dourados, MS. Disponível em: http://br-ie.org/pub/index.php/wie/article/view/3104/2612.

GUEDES, E. Um Estudo Observacional sobre a Disciplina Introdutória de Programação. In: III Congresso de Informática na Educação/XX Workshop de Informática na Escola, 2014, Dourados, MS. Disponível em: http://brie.org/pub/index.php/wie/article/view/3140/2648.

OLIVEIRA, M. et al. Ensino de lógica de programação no ensino fundamental utilizando o Scratch. In: XXXIV Congresso da Sociedade Brasileira de Computação, 2014, Brasília, DF. Disponível em: http://csbc2014.cic.unb.br/index.php/anais-menu.

SILVA, G., SOUZA, J. e SILVA, L. Aplicação da Ferramenta Scratch para o Aprendizado de Programação no Ensino Fundamental I. In: V Congresso Brasileiro de Informática na Educação, 2016, Uberlândia - MG. Disponível em: http://brie.org/pub/index.php/wcbie/article/view/7054.

SOUZA, S. e CASTRO, T. Investigação em programação com Scratch para crianças: uma revisão sistemática da literatura. In: V Congresso Brasileiro de Informática na Educação, 2016, Uberlândia - MG. Disponível em: http://www.brie.org/pub/index.php/wcbie/article/view/7033. 